Article

\title{
Genotoxic Bystander Signals from Irradiated Human Mesenchymal Stromal Cells Mainly Localize in the 10-100 kDa Fraction of Conditioned Medium
}

\author{
Vanessa Kohl ${ }^{1}$, Alice Fabarius ${ }^{1}$, Oliver Drews ${ }^{2}$, Miriam Bierbaum ${ }^{3}$, Ahmed Jawhar ${ }^{4}$, Ali Darwich ${ }^{4}(\mathbb{D}$, \\ Christel Weiss ${ }^{5}$, Johanna Flach ${ }^{1}$, Susanne Brendel ${ }^{1}$, Helga Kleiner ${ }^{1}$, Wolfgang Seifarth ${ }^{1}$, \\ Wolf-Karsten Hofmann ${ }^{1}$ and Henning D. Popp ${ }^{1, *(1)}$
}

check for

updates

Citation: Kohl, V.; Fabarius, A.; Drews, O.; Bierbaum, M.; Jawhar, A.; Darwich, A.; Weiss, C.; Flach, J.; Brendel, S.; Kleiner, H.; et al. Genotoxic Bystander Signals from Irradiated Human Mesenchymal Stromal Cells Mainly Localize in the 10-100 kDa Fraction of Conditioned Medium. Cells 2021, 10, 827. https:/ / doi.org/10.3390/cells10040827

Academic Editor: Ciro Isidoro

Received: 23 March 2021

Accepted: 4 April 2021

Published: 7 April 2021

Publisher's Note: MDPI stays neutral with regard to jurisdictional claims in published maps and institutional affiliations.

Copyright: (c) 2021 by the authors. Licensee MDPI, Basel, Switzerland. This article is an open access article distributed under the terms and conditions of the Creative Commons Attribution (CC BY) license (https:/ / creativecommons.org/licenses/by/ $4.0 /)$.
1 Department of Hematology and Oncology, Medical Faculty Mannheim, Heidelberg University, 68167 Mannheim, Germany; Vanessa.Kohl@medma.uni-heidelberg.de (V.K.);

Alice.Fabarius@medma.uni-heidelberg.de (A.F.); Johanna.Flach@medma.uni-heidelberg.de (J.F.); Susanne.Brendel@medma.uni-heidelberg.de (S.B.); Helga.Kleiner@medma.uni-heidelberg.de (H.K.); Wolfgang.Seifarth@medma.uni-heidelberg.de (W.S.); w.k.hofmann@medma.uni-heidelberg.de (W.-K.H.)

2 Department of Clinical Chemistry, University Medical Center Mannheim, 68167 Mannheim, Germany; Oliver.Drews@umm.de

3 Department of Radiation Oncology, Medical Faculty Mannheim, Heidelberg University, 68167 Mannheim, Germany; Miriam.Bierbaum@medma.uni-heidelberg.de

4 Department of Orthopedics and Trauma Surgery, Medical Faculty Mannheim, Heidelberg University, 68167 Mannheim, Germany; Ahmed.Jawhar@medma.uni-heidelberg.de (A.J.); alidarwich@mail.com (A.D.)

5 Department of Medical Statistics and Biomathematics, Medical Faculty Mannheim, Heidelberg University, 68167 Mannheim, Germany; Christel.Weiss@medma.uni-heidelberg.de

* Correspondence: Henning.Popp@medma.uni-heidelberg.de; Tel.: +49-621-383-71307

Abstract: Genotoxic bystander signals released from irradiated human mesenchymal stromal cells (MSC) may induce radiation-induced bystander effects (RIBEs) in human hematopoietic stem and progenitor cells (HSPC), potentially causing leukemic transformation. Although the source of bystander signals is evident, the identification and characterization of these signals is challenging. Here, RIBEs were analyzed in human CD34+ cells cultured in distinct molecular size fractions of medium, conditioned by 2 Gy irradiated human MSC. Specifically, $\gamma \mathrm{H} 2 \mathrm{AX}$ foci (as a marker of DNA double-strand breaks) and chromosomal instability were evaluated in CD34+ cells grown in approximate (I) $<10 \mathrm{kDa}$, (II) $10-100 \mathrm{kDa}$ and (III) $>100 \mathrm{kDa}$ fractions of MSC conditioned medium and un-/fractionated control medium, respectively. Hitherto, significantly increased numbers of $\gamma \mathrm{H} 2 \mathrm{AX}$ foci $(p=0.0286)$ and aberrant metaphases $(p=0.0022)$ were detected in CD34+ cells grown in the (II) $10-100 \mathrm{kDa}$ fraction $(0.67 \pm 0.10 \gamma \mathrm{H} 2 \mathrm{AX}$ foci per CD34+ cell $\vee 3.8$ \pm 0.3 aberrant metaphases per CD34+ cell sample; mean $\pm \mathrm{SEM}$ ) when compared to (I) $<10 \mathrm{kDa}$ $(0.19 \pm 0.01 \vee 0.3 \pm 0.2)$ or $(\mathrm{III})>100 \mathrm{kDa}$ fractions $(0.23 \pm 0.04 \vee 0.4 \pm 0.4)$ or un-/fractionated control medium $(0.12 \pm 0.01 \vee 0.1 \pm 0.1)$. Furthermore, RIBEs disappeared after heat inactivation of medium at $75^{\circ} \mathrm{C}$. Taken together, our data suggest that RIBEs are mainly mediated by the heatsensitive (II) 10-100 kDa fraction of MSC conditioned medium. We postulate proteins as RIBE mediators and in-depth proteome analyses to identify key bystander signals, which define targets for the development of next-generation anti-leukemic drugs.

Keywords: bystander signals; radiation-induced bystander effects; mesenchymal stromal cells; CD34+ cells; leukemia

\section{Introduction}

Genotoxic bystander signals released from irradiated human mesenchymal stromal cells (MSC) may induce radiation-induced bystander effects (RIBEs) in non-irradiated human hematopoietic stem and progenitor cells (HSPC) potentially initiating myeloid neo-plasms (MN). In the 2016 WHO classification, MN that arise after irradiation therapy 
are referred to as therapy-related $\mathrm{MN}$ (t-MN) [1]. As t-MN are characterized by high-risk genetic alterations $[2,3]$ and a particularly worse prognosis [4,5], anti-leukemic therapies are urgently needed.

Generally, RIBEs describe 'out-of-field' effects of irradiation in non-irradiated cells that are comparable to effects in irradiated cells. RIBEs may emerge as DNA damage (e.g., increased $\gamma \mathrm{H} 2 \mathrm{AX}$ foci, gene mutations, chromosomal aberrations, micronuclei), cell death (e.g., apoptosis, necrosis), and induction of cell survival mechanisms (e.g., adaptive response, DNA repair) [6-9]. Bystander signals are assumed to be initiated in irradiated cells by calcium fluxes [10] and mitochondrial metabolites [11-13]. Afterwards, small molecules like nitric oxide (NO) [14] and reactive oxygen species (ROS) [15] may be transmitted from irradiated cells to non-irradiated bystander cells. Next, regulators, such as nuclear factor-kappa B (NF-kappa B) [13] and transforming growth factor beta-1 (TGFbeta-1) [16,17], may be released by exocytosis. In addition, a role of gap junctions in intercellular transmission has been described $[18,19]$. Furthermore, cysteine protease cathepsin B is a proven bystander signal [20]. Beyond that, microRNA and mitochondrial DNA might be secreted in exosomes/exosome-like vesicles and contribute to bystander signaling [21,22]. In the last step, NO [23], ROS [23], calcium fluxes [24,25] and distinct factors, such as MAP kinases [25] may be induced in affected bystander cells, thereby potentially initiating malignant transformation.

The analysis of bystander signals is a cutting-edge field in leukemia research. Here, irradiated healthy human MSC and healthy human CD34+ cells from the same donors were investigated in an in vitro model system that enables characterization of genotoxic signaling factors. Specifically, molecular size fractions of MSC conditioned medium of approximate (I) $<10 \mathrm{kDa}$ (corresponding to mediators such as small chemokines, cytokines, survival factors, microRNA), (II) 10-100 kDa (corresponding to mediators such as middle-sized growth factors, cytokines, transcription factors, mtDNA), and (III) $>100 \mathrm{kDa}$ molecular weight (corresponding to large mediators and structures such as exosomes) were used for culture of CD34+ cells of the same donors. Afterwards, RIBE were analyzed in exposed CD34+ cells in terms of DNA damage and chromosomal instability (CIN). The data may provide important information on the fraction of interest in MSC conditioned medium to be analyzed most profitable by in-depth proteome analysis for the identification of key bystander signals, which might contribute to the development of next-generation anti-leukemic drugs.

\section{Materials and Methods}

\subsection{Collection of Human Femoral Heads}

Femoral heads were collected from 7 patients with coxarthrosis ( 2 female, 5 males, mean age: 71 years, range 52-86 years) undergoing hip replacement.

\subsection{Isolation of Human MSC}

Bones were broken into fragments and incubated for $1 \mathrm{~h}$ at $37^{\circ} \mathrm{C}$ in phosphate-buffered saline (PBS) supplemented with $1 \mathrm{mg} / \mathrm{mL}$ collagenase type I (Thermo Fisher, Waltham, MA, USA). Supernatants were filtered in a cell strainer with $100 \mu \mathrm{m}$ nylon mesh pores (Greiner Bio-One, Kremsmünster, Austria). Afterwards, bone fragments retained in the cell strainer were transferred into StemMACS MSC Expansion Media XF (Miltenyi Biotec, Bergisch Gladbach, Germany) supplemented with $1 \%$ penicillin/streptomycin. Then, adherent MSC were expanded in T175 flasks in a humidified $5 \% \mathrm{CO}_{2}$ atmosphere at $37^{\circ} \mathrm{C}$ and passaged at $80 \%$ confluency.

\subsection{Isolation of Human CD34+ Cells}

CD34+ cells were isolated from bone marrow mononuclear cells by Ficoll density gradient centrifugation and magnetic-activated cell sorting using CD34 antibody-conjugated microbeads (Miltenyi Biotec). CD34+ cells were grown in a density of $3 \times 10^{5}$ cells $/ \mathrm{mL}$ in StemSpan SFEM II medium (Stemcell Technologies, Vancouver, BC, Canada) supplemented 
with StemSpan Myeloid Expansion supplement (SCF, TPO, G-CSF, GM-CSF) (Stemcell Technologies) and 1\% penicillin/streptomycin in a humidified 5\% $\mathrm{CO}_{2}$ atmosphere at $37^{\circ} \mathrm{C}$.

\subsection{Preparation of Fractions of MSC Conditioned Medium}

MSC were grown in T175 flasks until reaching 80\% confluency. MSC were rinsed in PBS and fresh StemSpan SFEM II medium was added. Afterwards, MSC were 2 Gy irradiated by 6 MV X-rays in a Versa HD linear accelerator (Elekta, Stockholm, Sweden), while control MSC were not irradiated. MSC conditioned medium and control medium were obtained from irradiated and non-irradiated MSC, respectively, after $4 \mathrm{~h}$ incubation at $37^{\circ} \mathrm{C}$. The collected medium was centrifuged $(4000 \times g, 10 \mathrm{~min})$ and supernatants were filtered through $10 \mathrm{kDa}$ molecular weight cut-off (MWCO) ultrafiltration centrifugal filter units (Amicon Ultra, Merck, Darmstadt, Germany) to obtain (I) approximate $<10 \mathrm{kDa}$ fractions of MSC conditioned and control medium, respectively. Next, the supernatants above the filter were adjusted with fresh medium to the original volume and filtered through $100 \mathrm{kDa}$ MWCO ultrafiltration centrifugal filter units to obtain (II) approximate 10-100 kDa fractions of MSC conditioned and control medium, respectively. Finally, the supernatants above the filter were adjusted with fresh medium to the original volume and then contained (III) approximate $>100 \mathrm{kDa}$ fractions of MSC conditioned and control medium, respectively. The distinct fractions (I)-(III) of MSC conditioned and control medium were stored at $-20^{\circ} \mathrm{C}$.

\subsection{Heat Inactivation of MSC Conditioned and Control Medium}

Heat inactivation of RIBE mediators in un-/fractionated MSC conditioned medium and un-/fractionated control medium was performed by incubation at $75^{\circ} \mathrm{C}$ for $20 \mathrm{~min}$.

\subsection{RIBE Analysis}

RIBE were analyzed in CD34+ cell samples (\#1-6) at day 6 after culture for 3 days in native medium followed by culture for 3 days in un-/fractionated MSC conditioned medium or in un-/fractionated control medium, respectively. Additional experiments with CD34+ cell samples (\#5-7) were performed in MSC conditioned medium after heat inactivation.

\subsection{Immunofluorescence Staining of $\gamma H 2 A X$}

Immunofluorescence staining of $\gamma \mathrm{H} 2 \mathrm{AX}$ was performed in absolute $1 \times 10^{5} \mathrm{CD} 34+$ cells using a JBW301 mouse monoclonal anti- $\gamma \mathrm{H} 2 \mathrm{AX}$ antibody (1:500) (\#05-636, Merck) and an Alexa Fluor 488-conjugated goat anti-mouse secondary antibody (1:500) (\#A11001, Thermo Fisher) [26,27]. At least 50 nuclei were analyzed in each sample.

\subsection{Cytogenetic Analysis}

Cytogenetic analysis of G-banded chromosomes was performed in absolute $2 \times 10^{6}$ CD34+ cells according to standard procedures [28]. At least 25 metaphases were analyzed in each sample following the international system for human cytogenetic nomenclature (ISCN) 2016 [29]. Sporadic chromosomal alterations (e.g., chromatid breaks (chtb), chromosome breaks, trisomy) were included in the karyotype (non-clonal events) when detected in at least one metaphase. Because tetraploid/octaploid metaphases were detected at low frequency in CD34+ cells grown in control medium as well, they were only included in karyotypes in case of clonality (tetraploidy and/or octaploidy in two or more metaphases) according to the ISCN 2016.

\subsection{Statistical Analysis}

Statistical analysis was performed with SAS software, release 9.4 (SAS Institute, Cary, NC, USA). For quantitative variables, mean values and standard deviations were calculated. Categorical factors are presented with absolute and relative frequencies. In order to compare more than two groups, Kruskal-Wallis tests were performed. For pairwise group 
comparisons, exact Wilcoxon two-sample tests were used. In general, test results with $p<0.05$ were considered as statistically significant.

\section{Results}

\subsection{DNA Damage in Human CD34+ Cells}

$\gamma \mathrm{H} 2 \mathrm{AX}$ foci were analyzed in human CD34+ cell samples (4 patients; $\sum 32$ samples) expanded for 3 days in native medium followed by culture for 3 days in un-/fractionated MSC conditioned or un-/fractionated control medium, respectively (Figure 1a,b). Increased numbers of $\gamma \mathrm{H} 2 \mathrm{AX}$ foci (general $p=0.0068$ (Kruskal-Wallis test); pairwise comparison each $p=0.0286$ (Wilcoxon two-sample test)) were detected in CD34+ cells grown in the (II) $10-100 \mathrm{kDa}$ fraction of MSC conditioned medium $(0.67 \pm 0.10 \gamma \mathrm{H} 2 \mathrm{AX}$ foci per CD34+ cell; mean \pm standard error of mean (SEM)) when compared to numbers of $\gamma \mathrm{H} 2 \mathrm{AX}$ foci in CD34+ cells grown in (I) $<10 \mathrm{kDa}(0.19 \pm 0.01 \gamma \mathrm{H} 2 \mathrm{AX}$ foci per CD34+ cell $)$ and (III) $>100 \mathrm{kDa}$ fractions $(0.23 \pm 0.04 \gamma \mathrm{H} 2 \mathrm{AX}$ foci per CD34+ cell) of MSC conditioned medium or in un-/fractionated control medium $(0.12 \pm 0.01 \gamma \mathrm{H} 2 \mathrm{AX}$ foci per CD34+ cell). Since $\gamma \mathrm{H} 2 \mathrm{AX}$ foci are a marker of DNA double-strand breaks (DSB), our findings suggest that DNA damage signaling factors mainly localize in the (II) 10-100 kDa fraction of MSC conditioned medium.

\subsection{Chromosomal Instability in Human CD34+ Cells}

Metaphases were analyzed in human CD34+ cell samples (patients \#1-6; $\sum 46$ samples) expanded for 3 days in native medium followed by culture for 3 days in un-/fractionated MSC conditioned or un-/fractionated control medium, respectively (Figure 1c,d, Table 1). Increased numbers of aberrant metaphases (general $p=0.0007$ (Kruskal-Wallis test); pairwise comparison each $p=0.0022$ (Wilcoxon two-sample test)) were detected in CD34+ cells grown in the (I) 10-100 kDa fraction of MSC conditioned medium (3.8 \pm 0.3 aberrant metaphases per CD34+ cell sample; mean \pm SEM) when compared to numbers of aberrant metaphases in CD34+ cells grown in (II) $<10 \mathrm{kDa}(0.3 \pm 0.2$ aberrant metaphases per CD34+ cell sample) and (III) $>100 \mathrm{kDa}$ fractions $(0.4 \pm 0.4$ aberrant metaphases per CD34+ cell sample) of MSC conditioned medium or in un-/fractionated control medium $(0.1 \pm 0.1$ aberrant metaphases per CD34+ cell sample). More precisely, distinct chromatid breaks (chtb), e.g., $\operatorname{chtb}(5 q)$ and $\operatorname{chtb}(7 q)$ as well as aneuploidies, e.g., tetraploidies and octaploidies, were observed in CD34+ cells grown in the (II) 10-100 kDa fraction of MSC conditioned medium. In addition, distinct chtb, e.g., $\operatorname{chtb}(2), \operatorname{chtb}(9)$ and $\operatorname{chtb}(11)$ as well as aneuploidies, e.g., tetraploidies and octaploidies, were observed in CD34+ cells grown in unfractionated MSC conditioned medium. It has to be noted, that loss of chromosome $\mathrm{Y}$ in sample \#5 is a common finding in elderly men occurring at a frequency of 5-10\% [30,31]. Further, few chromosomal aberrations, e.g., $\operatorname{chtb}(14 \mathrm{q})$ and aneuploidies, e.g., tetraploidies, were detected at very low frequencies in (I) $<10 \mathrm{kDa}$ and (III) $>100 \mathrm{kDa}$ fractions of MSC conditioned medium, which might arise sporadically or due to limitations in the accuracy of the filtration process.

Finally, heat inactivation of unfractionated MSC conditioned medium and unfractionated control medium (patients \#5-7; $\sum 6$ samples) resulted in increased doubling times of CD34+ cells (Table 2). While proliferation of CD34+ cells in sample \#5 was reduced, the proliferation of CD34+ cells in samples \#6 and \#7 was almost regular. All metaphases in CD34+ cells in samples \#5 and \#6 displayed a normal karyotype when grown in heat-inactivated MSC conditioned medium or control medium. Notably, two tetraploidies were observed in CD34+ cells in sample \#7 when grown in heat-inactivated MSC conditioned medium or control medium with an additional chtb(4q) occurring in the same sample when grown in heat-inactivated conditioned medium. While tetraploidies occur frequently in CD34+ cells grown in MSC conditioned medium, they occur sporadically at low frequencies in healthy CD34+ cells and might be even more frequent in aging CD34+ cells of the elderly. Further, the reduced proliferation especially in sample \#5 could lead to a lowered number of irregular karyotypes due to cell cycle arrests. Nonetheless, the disappearance of RIBEs 
in the whole in CD34+ cells grown in heat-inactivated MSC conditioned medium suggests heat-sensitive structures as critical bystander signals.

(a)

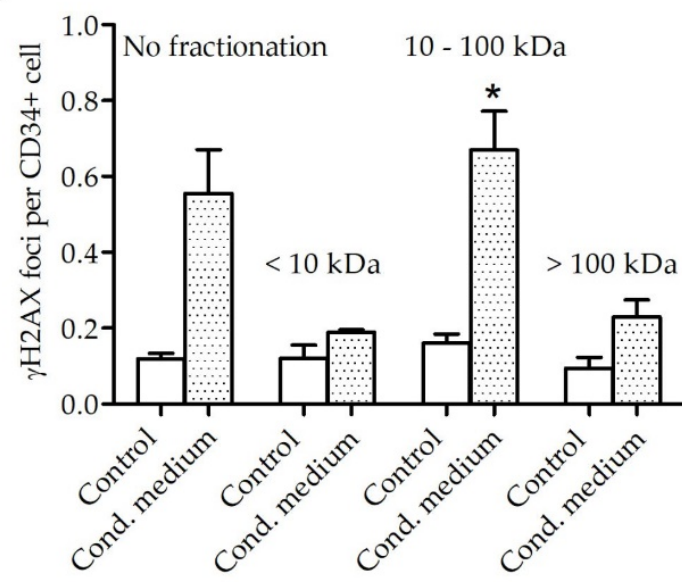

(c)

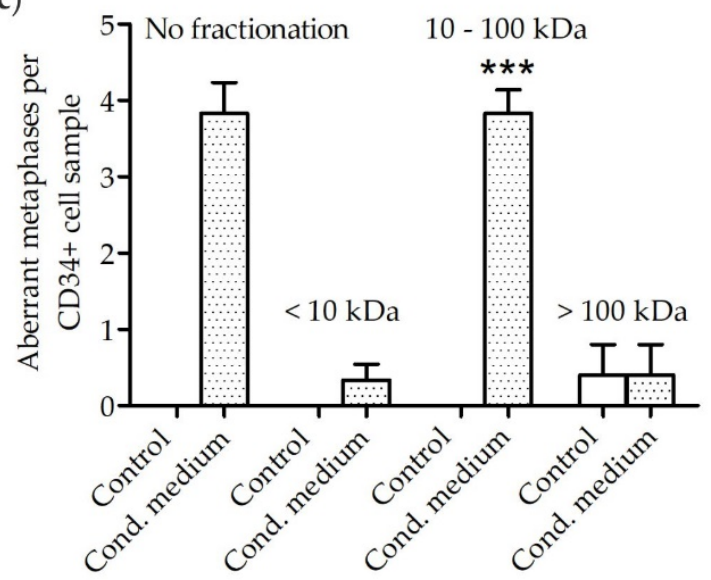

(b)

$\gamma \mathrm{H} 2 \mathrm{AX}$ foci CD34+ cells

No fractionation $<10 \mathrm{kDa} \quad 10-100 \mathrm{kDa}>100 \mathrm{kDa}$

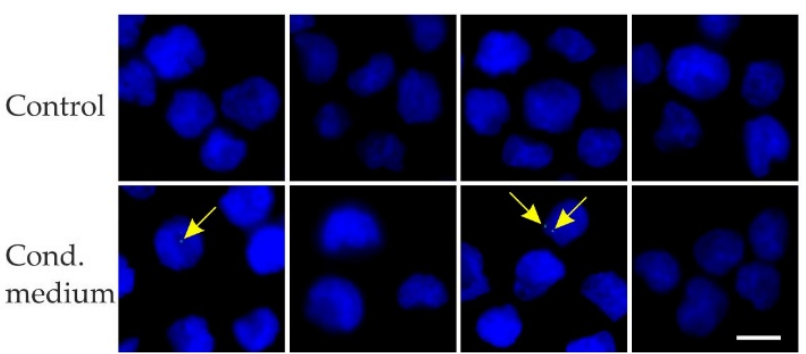

(d)

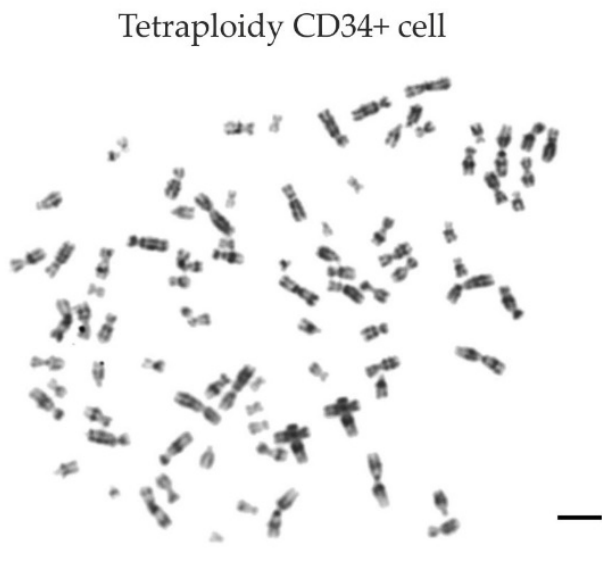

Figure 1. Radiation-induced bystander effects in CD34+ cells grown for 3 days in distinct molecular size fractions of medium conditioned by 2 Gy irradiated mesenchymal stromal cells (MSC) and un-/fractionated control medium. (a) $\gamma \mathrm{H} 2 \mathrm{AX}$ foci levels in CD34+ cells grown in (I) $<10 \mathrm{kDa}$, (II) 10-100 kDa and (III) $>100 \mathrm{kDa}$ fractions of MSC conditioned medium and in un-/fractionated control medium. ${ }^{*} p=0.0068$ (Kruskal-Wallis test) and $p=0.0286$ (Wilcoxon two-sample test) when compared to numbers of $\gamma \mathrm{H} 2 \mathrm{AX}$ foci in CD34+ cells grown in (I) $<10 \mathrm{kDa}$ and (III) $>100 \mathrm{kDa}$ fractions or in un-/fractionated control medium. (b) Exemplary images of $\gamma \mathrm{H} 2 \mathrm{AX}$ foci (green, Alexa-488) in nuclei (blue, DAPI) of CD34+ cells of patient \#2. Scale bar, $5 \mu \mathrm{m}$. (c) Number of aberrant metaphases in CD34+ cells grown in (I) $<10 \mathrm{kDa}$, (II) $10-100 \mathrm{kDa}$ and (III) $>100 \mathrm{kDa}$ fractions of MSC conditioned medium and in un- $/$ fractionated control medium. ${ }^{* *} p=$ 0.0007 (Kruskal-Wallis test) and $p=0.0022$ (Wilcoxon two-sample test) when compared to number of aberrant metaphases in CD34+ cells grown in (I) $<10 \mathrm{kDa}$ and (III) $>100 \mathrm{kDa}$ fractions or in un-/fractionated control medium. (d) Exemplary tetraploidy of a CD34+ cell grown in the (II) 10-100 kDa fraction of MSC conditioned medium. Scale bar, $10 \mu \mathrm{m}$. 


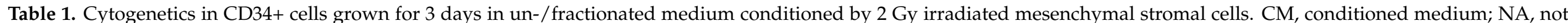
assessed; $\mathrm{Pt}$, patient; [number] = number of metaphases.

\begin{tabular}{|c|c|c|c|c|c|c|c|c|c|}
\hline \multirow[t]{3}{*}{$\mathbf{P t}$} & \multirow{3}{*}{$\begin{array}{c}\text { Age/ } \\
\text { Sex }\end{array}$} & \multirow{2}{*}{\multicolumn{2}{|c|}{ Cytogenetics CD34+ Cells }} & \multirow{2}{*}{\multicolumn{2}{|c|}{$\begin{array}{c}\text { Cytogenetics CD34+ Cells } \\
<10 \mathrm{kDa}\end{array}$}} & \multicolumn{2}{|c|}{ Cytogenetics CD34+ Cells } & \multicolumn{2}{|c|}{ Cytogenetics CD34+ Cells } \\
\hline & & & & & & \multicolumn{2}{|c|}{$10-100 \mathrm{kDa}$} & \multicolumn{2}{|c|}{$>100 \mathrm{kDa}$} \\
\hline & & Control & $\mathbf{C M}$ & Control & $\mathbf{C M}$ & Control & $\mathbf{C M}$ & Control & $\mathrm{CM}$ \\
\hline$\# 1$ & $84 / q$ & $46, X X[25]$ & $\begin{array}{c}46, X X[20] \\
53, X X,+1,+2,+5,+6,+14,+21,+22[1] \\
92, X X X X[4]\end{array}$ & $46, X X[20]$ & $46, X X[25]$ & $46, X X[25]$ & $\begin{array}{c}46, X X[22] \\
92, X X X X[3]\end{array}$ & NA & NA \\
\hline \#2 & $65 / 0^{7}$ & $46, X Y[25]$ & $\begin{array}{c}46, X Y[20] \\
92, X X X X[1] \\
\text { 184,XXXXYYYY,chtb(11)(q23)[1] } \\
46, X Y, \operatorname{dup}(13 q)[1] \\
47, X Y,+21, \operatorname{chtb}(11)(\mathrm{p} 12)[1] \\
\text { 46,XY,chtb(9)(12)[1] }\end{array}$ & $46, X Y[25]$ & $46, X Y[22]$ & $46, X Y[25]$ & $\begin{array}{c}46, X Y[21] \\
92, X X X X[2] \\
69, X X Y[1] \\
47, X Y,+3[1]\end{array}$ & $46, X Y[25]$ & $46, X Y[25]$ \\
\hline \#3 & $62 / 0^{7}$ & $46, X Y[25]$ & $\begin{array}{c}46, X Y[22] \\
92, X X Y Y[3]\end{array}$ & $46, \mathrm{XY}[25]$ & $46, X Y[25]$ & $46, X Y[25]$ & $\begin{array}{c}46, \mathrm{XY}[20] \\
92, \mathrm{XXYY}[3] \\
46, \mathrm{XY}, \mathrm{chtb}(5)(\mathrm{q} 33)[1] \\
46, \mathrm{XY},+\mathrm{f}[1]\end{array}$ & $46, X Y[25]$ & $46, X Y[25]$ \\
\hline$\# 4$ & $62 / 0^{7}$ & $46, X Y[25]$ & $\begin{array}{c}46, X Y[21] \\
92, X X Y Y[3] \\
92, X X Y Y, \operatorname{chtb}(2 p)[1]\end{array}$ & $46, X Y[25]$ & $\begin{array}{c}46, X Y[23] \\
46, X Y, \operatorname{chtb}(14 q)[1]\end{array}$ & $46, X Y[25]$ & $\begin{array}{c}\text { 46,XY[22] } \\
\text { 92,XXYY[1] } \\
184, X X X X Y Y Y Y[1] \\
46, X Y, \operatorname{chtb}(7 \mathrm{p})[1]\end{array}$ & $\begin{array}{c}\text { 46,XY[23] } \\
184, X X X X Y Y Y Y[2]\end{array}$ & $46, X Y[25]$ \\
\hline \#5 & $85 / 0^{7}$ & $\begin{array}{c}46, X Y[13] \\
45, X,-Y[12]\end{array}$ & $\begin{array}{c}46, X Y[10] \\
45, X,-Y[12] \\
\text { 90,XX,-Y,-Y[1] } \\
\text { 92,XXYY[1] } \\
\text { 184,XXXXYYYY[1] }\end{array}$ & $\begin{array}{c}46, X Y[5] \\
45, X,-Y[20]\end{array}$ & $\begin{array}{c}46, X Y[7] \\
45, X,-Y[18]\end{array}$ & $\begin{array}{l}46, X Y[21] \\
45, X,-Y[4]\end{array}$ & $\begin{array}{c}46, \mathrm{XY}[18] \\
45, \mathrm{X},-\mathrm{Y}[3] \\
92, \mathrm{XXYY}[2] \\
47, \mathrm{XY},+2[1] \\
50, \mathrm{XY},+1,+7,+9,+14[1]\end{array}$ & $\begin{array}{c}46, X Y[10] \\
45, X,-Y[15]\end{array}$ & $\begin{array}{c}46, X Y[13] \\
45, X,-Y[7] \\
92, X X Y Y[1] \\
90, X X,-Y,-Y[1]\end{array}$ \\
\hline \#6 & $52 / 0^{7}$ & $46, X Y[25]$ & $\begin{array}{c}46, X Y[22] \\
92, X X Y Y[2] \\
184, X X X X Y Y Y Y 1]\end{array}$ & $46, X Y[25]$ & $\begin{array}{c}46, X Y[24] \\
46, X Y,+f[1]\end{array}$ & $46, X Y[21]$ & $\begin{array}{c}46, X Y[21] \\
\text { 92,XXYY[3] } \\
184, X X X X Y Y Y Y[1]\end{array}$ & $46, X Y[25]$ & $46, X Y[25]$ \\
\hline
\end{tabular}




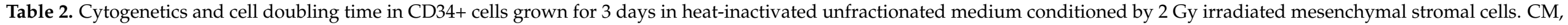
conditioned medium; $\mathrm{Pt}$, patient; [number] = number of metaphases.

\begin{tabular}{|c|c|c|c|c|c|c|c|c|c|}
\hline \multirow[t]{2}{*}{$\mathbf{P t}$} & \multirow{2}{*}{$\begin{array}{c}\text { Age/ } \\
\text { Sex }\end{array}$} & \multicolumn{2}{|c|}{ Cytogenetics CD34+ Cells } & \multicolumn{2}{|c|}{ Cytogenetics CD34+ Cells } & \multicolumn{2}{|c|}{ Cell Doubling Time (Days) } & \multicolumn{2}{|c|}{ Cell Doubling Time (Days) } \\
\hline & & Control & $\mathrm{CM}$ & Control & $\mathbf{C M}$ & Control & $\mathbf{C M}$ & Control & $\mathrm{CM}$ \\
\hline & & \multicolumn{2}{|c|}{ No Heat Inactivation } & \multicolumn{2}{|c|}{+ Heat Inactivation } & \multicolumn{2}{|c|}{ No Heat Inactivation } & \multicolumn{2}{|c|}{ +Heat Inactivation } \\
\hline \#5 & $85 / 0^{7}$ & $\begin{array}{c}46, X Y[13] \\
45, X,-Y[12]\end{array}$ & $\begin{array}{c}46, X Y[10] \\
45, X,-Y[12] \\
90, X X,-Y,-Y[1] \\
92, X X Y Y[1] \\
\text { 184,XXXXYYYY[1] }\end{array}$ & $46, X Y[15]$ & $46, \mathrm{XY}[14]$ & 1.0 & 1.0 & 1.9 & 1.5 \\
\hline \#7 & $86 / q$ & $46, X X[25]$ & $\begin{array}{c}46, X X[20] \\
46, X X, \operatorname{chtb}(10 \mathrm{q})[1] \\
46, X X, \operatorname{del}(19)(\mathrm{p} 10)[1] \\
\text { 92,XXXX[2] } \\
\text { 184,XXXXXXXX[1] }\end{array}$ & $\begin{array}{c}46, X X[23] \\
92, X X X X[2]\end{array}$ & $\begin{array}{c}46, X X[22] \\
92, X X X X[2] \\
46, X X, \operatorname{chtb}(4 q)[1]\end{array}$ & 1.3 & 1.2 & 1.8 & 1.4 \\
\hline
\end{tabular}




\section{Discussion}

Genotoxic bystander signals released from irradiated human MSC may induce DNA damage and CIN in human HSPC potentially initiating MN. While increased DNA damage and CIN are readily inducible in human CD34+ cells by exposure to MSC conditioned medium, the genotoxic bystander signals in MSC conditioned medium remain largely uncharacterized yet. Therefore, our study was designed to investigate the molecular features of bystander signals in terms of molecular weight and potential protein characteristics. For this purpose, approximate (I) $<10 \mathrm{kDa}$, (II) $10-100 \mathrm{kDa}$ and (III) $>100 \mathrm{kDa}$ fractions of MSC conditioned medium were first generated and then unfractionated MSC conditioned medium was heat-inactivated for co-culture experiments in healthy human CD34+ cells of the same donors.

Immunofluorescence microscopy of $\gamma \mathrm{H} 2 \mathrm{AX}$ foci, which are a marker of DSB, is widely used in RIBE analysis [32-34]. Increased numbers of $\gamma \mathrm{H} 2 \mathrm{AX}$ foci were detected in CD34+ cells grown in the (II) 10-100 kDa fraction of MSC conditioned medium when compared to low numbers of $\gamma \mathrm{H} 2 \mathrm{AX}$ foci in CD34+ cells grown in (I) $<10 \mathrm{kDa}$ and (III) $>100 \mathrm{kDa}$ fractions of MSC conditioned medium or in un-/fractionated control medium. Our data are in line with similarly increased numbers of chtb detected in CD34+ cells grown in the (II) 10-100 kDa fraction of MSC conditioned medium. Importantly, chtb may activate oncogenes or inactivate tumor suppressor genes, thus providing a potential mechanistic link to the initiation of MN.

Cytogenetic analysis is a suitable method for analysis of RIBE and has been applied in mouse HSPC $[35,36]$. Increased numbers of aberrant metaphases were observed in CD34+ cells grown in the (II) 10-100 kDa fraction of MSC conditioned medium when compared to low numbers of aberrant metaphases in CD34+ cells grown in (I) $<10 \mathrm{kDa}$ and (III) $>100 \mathrm{kDa}$ fractions of MSC conditioned medium or in un-/ fractionated control medium. In particular, the number of tetraploidies was increased in the (II) $10-100 \mathrm{kDa}$ fraction of MSC conditioned medium. Generally, tetraploidies may occur by chromosomal non-disjunction during mitosis or cytokinesis failure [37]. Further, tetrapolidies are found in about $1 \%$ of AML but $13 \%$ of t-AML cases [38]. Hence, our finding of increased tetraploidies in CD34+ cells grown in the (II) 10-100 kDa fraction of MSC conditioned medium suggests a mechanistic link to the initiation of MN. Although tetraploidies occurred at very low frequency in CD34+ cells grown in control medium, this result is not contradictory to our interpretations but indicates that tetraploidies may randomly occur in vitro during the proliferation process itself. Furthermore, the detection of a clonal tetraploidy in CD34+ cells obtained from an 86-year-old female points to a possible link between tetraploidies and aging [37].

Heat inactivation of unfractionated MSC conditioned medium rescued exposed CD34+ cells from generating excessive chromosomal aberrations. Thus, RIBE mediators have a temperature-sensitive structure supporting the notion that the three-dimensional conformation of macromolecules, such as the native tertiary structure in proteins, confers specifically to the genotoxic effects in the (II) $10-100 \mathrm{kDa}$ fraction of MSC conditioned medium instead of the sheer presence of mediating macromolecules. Our data are in accordance with the results in previous studies demonstrating that heat inactivation of conditioned medium reconstituted cloning efficiencies and cell survival in exposed keratinocytes and chondrocytes, respectively $[39,40]$.

Our study may raise the question for the impact of molecules such as ROS and NO as potential RIBE mediators in the 10-100 kDa fraction of MSC conditioned medium. Considering that ROS and NO are rather short-lived mediator molecules, there might be no major impact of MSC released ROS and NO on detected RIBEs in CD34+ cells in our experiments. More likely, hitherto unknown mediators with a longer half-life may increase ROS and NO in exposed CD34+ cells grown in MSC conditioned medium. Furthermore, large exosomes can be excluded from playing a critical role as vehicles for RIBE mediators in the MSC conditioned medium. In addition, it is important to note that the release of bystander signals and the induction of RIBEs is tissue- and dose-specific thereby following 
a certain kinetic [41]. While molecules or ions may pass membranes in irradiated MSC by diffusion, gap junctions or ion channels in milliseconds, the synthesis and secretion of proteins by exocytosis and exosomes may take minutes to hours. Subsequently, DNA damage in CD34+ cells may occur in minutes [41], while the formation of complex cytogenetic aberrations during cell divisions requires hours to days. Hence, the time intervals of $4 \mathrm{~h}$ post-irradiation for generating MSC conditioned medium and the analysis of RIBEs in CD34+ cells 3 days after exposure to MSC conditioned medium are specific but might be appropriate for analyzing bystander signals and their potential role in $\mathrm{MN}$ initiation in vitro.

Finally, our work may have practical importance and contribute to the development of future clinical applications. We first suggest in-depth proteome analysis of the 10-100 $\mathrm{kDa}$ fraction of MSC conditioned medium for the identification of key bystander signals. Second, bystander signals should be validated for their oncogenic potential, for example by exposing healthy CD34+ cells to medium containing bystander signal-like recombinant proteins followed by analysis of genetic alterations and potential induction of leukemic clones. Third, monoclonal antibodies against specific bystander signals could be developed, that might then be applied as anti-leukemic prophylaxis after irradiation in pre-clinical studies and, finally, clinical trials.

\section{Conclusions}

In conclusion, our data demonstrate that substantial genotoxic bystander signals mainly localize in the (II) 10-100 kDa fraction of MSC conditioned medium and that these signals are heat-sensitive. Based on these biochemical properties, we postulate proteins as RIBE mediators, which should be further analyzed by an in-depth proteome analysis of the corresponding fraction. Ultimately, it has the potential to uncover the identity of key bystander signals, which is fundamental for the development of next-generation anti-leukemic drugs.

Author Contributions: Conceptualization, H.D.P. and O.D.; methodology, H.D.P., O.D. and A.F.; software, V.K. and A.F.; validation, V.K., A.F. and H.D.P.; formal analysis, C.W.; investigation, V.K., S.B. and A.F.; resources, H.K., A.D., A.J., M.B., W.S., A.F. and W.-K.H.; data curation, V.K., A.F. and H.D.P.; writing—original draft preparation, H.D.P.; writing—review and editing, O.D., J.F., W.S., A.F. and W.-K.H.; visualization, H.D.P.; supervision, A.F. and W.-K.H.; project administration, H.D.P.; funding acquisition, H.D.P. and A.F. All authors have read and agreed to the published version of the manuscript.

Funding: This work was supported by a Stefan Jentsch Fellowship from Deutsche Gesellschaft für DNA-Reparaturforschung (DGDR) (V.K.) and a grant from Deutsche José Carreras Leukämie-Stiftung (DJCLS 14 R/2017 to H.D.P. and A.F.).

Institutional Review Board Statement: The study was conducted according to the guidelines of the Declaration of Helsinki, and approved by the Institutional Review Board (Ethics Committee) of the Medical Faculty Mannheim, Heidelberg University, Germany (protocol code 2019-1128N, 12 March 2019).

Informed Consent Statement: Informed consent was obtained from all subjects involved in the study.

Data Availability Statement: Data are contained within the article.

Conflicts of Interest: The authors declare no conflict of interest. The funders had no role in the design of the study; in the collection, analyses, or interpretation of data; in the writing of the manuscript, or in the decision to publish the results.

\section{References}

1. Swerdlow, S.H.; Campo, E.; Harris, N.L.; Jaffe, E.S.; Pileri, S.A.; Stein, H.; Thiele, J. WHO Classification of Tumours of Haematopoietic and Lymphoid Tissues, 4th ed.; IARC: Lyon, France, 2017; pp. 153-155.

2. Ok, C.Y.; Patel, K.P.; Garcia-Manero, G.; Routbort, M.J;; Fu, B.; Tang, G.; Goswami, M.; Singh, R.; Kanagal-Shamanna, R.; Pierce, S.A.; et al. Mutational profiling of therapy-related myelodysplastic syndromes and acute myeloid leukemia by next generation sequencing, a comparison with de novo diseases. Leuk Res. 2015, 39, 348-354. [CrossRef] 
3. Wong, T.N.; Ramsingh, G.; Young, A.L.; Miller, C.A.; Touma, W.; Welch, J.S.; Lamprecht, T.L.; Shen, D.; Hundal, J.; Fulton, R.S.; et al. Role of TP53 mutations in the origin and evolution of therapy-related acute myeloid leukaemia. Nature 2015, 518, 552-555. [CrossRef]

4. Fianchi, L.; Pagano, L.; Piciocchi, A.; Candoni, A.; Gaidano, G.; Breccia, M.; Criscuolo, M.; Specchia, G.; Maria Pogliani, E.; Maurillo, L.; et al. Characteristics and outcome of therapy-related myeloid neoplasms: Report from the Italian network on secondary leukemias. Am. J. Hematol. 2015, 90, E80-E85. [CrossRef]

5. Granfeldt Ostgard, L.S.; Medeiros, B.C.; Sengelov, H.; Norgaard, M.; Andersen, M.K.; Dufva, I.H.; Friis, L.S.; Kjeldsen, E.; Marcher, C.W.; Preiss, B.; et al. Epidemiology and Clinical Significance of Secondary and Therapy-Related Acute Myeloid Leukemia: A National Population-Based Cohort Study. J. Clin. Oncol. 2015, 33, 3641-3649. [CrossRef] [PubMed]

6. Watson, G.E.; Lorimore, S.A.; Macdonald, D.A.; Wright, E.G. Chromosomal instability in unirradiated cells induced in vivo by a bystander effect of ionizing radiation. Cancer Res. 2000, 60, 5608-5611.

7. Nagasawa, H.; Little, J.B. Induction of sister chromatid exchanges by extremely low doses of alpha-particles. Cancer Res. 1992, 52, 6394-6396. [PubMed]

8. Zhou, H.; Randers-Pehrson, G.; Waldren, C.A.; Vannais, D.; Hall, E.J.; Hei, T.K. Induction of a bystander mutagenic effect of alpha particles in mammalian cells. Proc. Natl. Acad. Sci. USA 2000, 97, 2099-2104. [CrossRef]

9. Azzam, E.I.; de Toledo, S.M.; Raaphorst, G.P.; Mitchel, R.E. Low-dose ionizing radiation decreases the frequency of neoplastic transformation to a level below the spontaneous rate in C3H 10T1/2 cells. Radiat. Res. 1996, 146, 369-373. [CrossRef] [PubMed]

10. Shao, C.; Lyng, F.M.; Folkard, M.; Prise, K.M. Calcium fluxes modulate the radiation-induced bystander responses in targeted glioma and fibroblast cells. Radiat. Res. 2006, 166, 479-487. [CrossRef] [PubMed]

11. Chen, S.; Zhao, Y.; Han, W.; Zhao, G.; Zhu, L.; Wang, J.; Bao, L.; Jiang, E.; Xu, A.; Hei, T.K.; et al. Mitochondria-dependent signalling pathway are involved in the early process of radiation-induced bystander effects. Br. J. Cancer 2008, 98, 1839-1844 [CrossRef]

12. Tartier, L.; Gilchrist, S.; Burdak-Rothkamm, S.; Folkard, M.; Prise, K.M. Cytoplasmic irradiation induces mitochondrial-dependent 53BP1 protein relocalization in irradiated and bystander cells. Cancer Res. 2007, 67, 5872-5879. [CrossRef]

13. Zhou, H.; Ivanov, V.N.; Lien, Y.C.; Davidson, M.; Hei, T.K. Mitochondrial function and nuclear factor-kappaB-mediated signaling in radiation-induced bystander effects. Cancer Res. 2008, 68, 2233-2240. [CrossRef]

14. Shao, C.; Stewart, V.; Folkard, M.; Michael, B.D.; Prise, K.M. Nitric oxide-mediated signaling in the bystander response of individually targeted glioma cells. Cancer Res. 2003, 63, 8437-8442.

15. Li, J.; He, M.; Shen, B.; Yuan, D.; Shao, C. Alpha particle-induced bystander effect is mediated by ROS via a p53-dependent SCO2 pathway in hepatoma cells. Int. J. Radiat. Biol. 2013, 89, 1028-1034. [CrossRef]

16. Shao, C.; Folkard, M.; Prise, K.M. Role of TGF-beta1 and nitric oxide in the bystander response of irradiated glioma cells. Oncogene 2008, 27, 434-440. [CrossRef]

17. Gow, M.D.; Seymour, C.B.; Ryan, L.A.; Mothersill, C.E. Induction of bystander response in human glioma cells using high-energy electrons: A role for TGF-beta1. Radiat. Res. 2010, 173, 769-778. [CrossRef] [PubMed]

18. Shao, C.; Furusawa, Y.; Aoki, M.; Ando, K. Role of gap junctional intercellular communication in radiation-induced bystander effects in human fibroblasts. Radiat. Res. 2003, 160, 318-323. [CrossRef] [PubMed]

19. Azzam, E.I.; de Toledo, S.M.; Little, J.B. Direct evidence for the participation of gap junction-mediated intercellular communication in the transmission of damage signals from alpha -particle irradiated to nonirradiated cells. Proc. Natl. Acad. Sci. USA 2001, 98, 473-478. [CrossRef] [PubMed]

20. Peng, Y.; Zhang, M.; Zheng, L.; Liang, Q.; Li, H.; Chen, J.T.; Guo, H.; Yoshina, S.; Chen, Y.Z.; Zhao, X.; et al. Cysteine protease cathepsin B mediates radiation-induced bystander effects. Nature 2017, 547, 458-462. [CrossRef]

21. Xu, S.; Wang, J.; Ding, N.; Hu, W.; Zhang, X.; Wang, B.; Hua, J.; Wei, W.; Zhu, Q. Exosome-mediated microRNA transfer plays a role in radiation-induced bystander effect. RNA Biol. 2015, 12, 1355-1363. [CrossRef] [PubMed]

22. Ariyoshi, K.; Miura, T.; Kasai, K.; Fujishima, Y.; Nakata, A.; Yoshida, M. Radiation-Induced Bystander Effect is Mediated by Mitochondrial DNA in Exosome-Like Vesicles. Sci. Rep. 2019, 9, 9103. [CrossRef] [PubMed]

23. Jella, K.K.; Moriarty, R.; McClean, B.; Byrne, H.J.; Lyng, F.M. Reactive oxygen species and nitric oxide signaling in bystander cells. PLoS ONE 2018, 13, e0195371. [CrossRef]

24. Lyng, F.M.; Howe, O.L.; McClean, B. Reactive oxygen species-induced release of signalling factors in irradiated cells triggers membrane signalling and calcium influx in bystander cells. Int. J. Radiat. Biol. 2011, 87, 683-695. [CrossRef]

25. Lyng, F.M.; Maguire, P.; McClean, B.; Seymour, C.; Mothersill, C. The involvement of calcium and MAP kinase signaling pathways in the production of radiation-induced bystander effects. Radiat. Res. 2006, 165, 400-409. [CrossRef]

26. Popp, H.D.; Naumann, N.; Brendel, S.; Henzler, T.; Weiss, C.; Hofmann, W.K.; Fabarius, A. Increase of DNA damage and alteration of the DNA damage response in myelodysplastic syndromes and acute myeloid leukemias. Leuk Res. 2017, 57, 112-118. [CrossRef]

27. Popp, H.D.; Brendel, S.; Hofmann, W.K.; Fabarius, A. Immunofluorescence Microscopy of gammaH2AX and 53BP1 for Analyzing the Formation and Repair of DNA Double-strand Breaks. J. Vis. Exp. 2017, 129, 56617.

28. Heim, S.; Mitelman, F. Cancer Cytogenetics, 3rd ed.; Wiley-Blackwell: Hoboken, NJ, USA, 2009; pp. 9-16.

29. McGowan-Jordan, J.; Simons, A.; Schmid, M. ISCN 2016 An International System for Human Cytogenetic Nomenclature (2016); Karger: Basel, Switzerland, 2016. 
30. Jacobs, P.A.; Brunton, M.; Court Brown, W.M.; Doll, R.; Goldstein, H. Change of human chromosome count distribution with age: Evidence for a sex differences. Nature 1963, 197, 1080-1081. [CrossRef]

31. Pierre, R.V.; Hoagland, H.C. Age-associated aneuploidy: Loss of Y chromosome from human bone marrow cells with aging. Cancer 1972, 30, 889-894. [CrossRef]

32. Sokolov, M.V.; Dickey, J.S.; Bonner, W.M.; Sedelnikova, O.A. gamma-H2AX in bystander cells: Not just a radiation-triggered event, a cellular response to stress mediated by intercellular communication. Cell Cycle 2007, 6, 2210-2212. [CrossRef]

33. Sedelnikova, O.A.; Nakamura, A.; Kovalchuk, O.; Koturbash, I.; Mitchell, S.A.; Marino, S.A.; Brenner, D.J.; Bonner, W.M. DNA double-strand breaks form in bystander cells after microbeam irradiation of three-dimensional human tissue models. Cancer Res. 2007, 67, 4295-4302. [CrossRef]

34. Dickey, J.S.; Zemp, F.J.; Altamirano, A.; Sedelnikova, O.A.; Bonner, W.M.; Kovalchuk, O. H2AX phosphorylation in response to DNA double-strand break formation during bystander signalling: Effect of microRNA knockdown. Radiat. Prot. Dosim. 2011, 143, 264-269. [CrossRef] [PubMed]

35. Lorimore, S.A.; McIlrath, J.M.; Coates, P.J.; Wright, E.G. Chromosomal instability in unirradiated hemopoietic cells resulting from a delayed in vivo bystander effect of gamma radiation. Cancer Res. 2005, 65, 5668-5673. [CrossRef]

36. Lorimore, S.A.; Chrystal, J.A.; Robinson, J.I.; Coates, P.J.; Wright, E.G. Chromosomal instability in unirradiated hemaopoietic cells induced by macrophages exposed in vivo to ionizing radiation. Cancer Res. 2008, 68, 8122-8126. [CrossRef]

37. Tanaka, K.; Goto, H.; Nishimura, Y.; Kasahara, K.; Mizoguchi, A.; Inagaki, M. Tetraploidy in cancer and its possible link to aging. Cancer Sci. 2018, 109, 2632-2640. [CrossRef] [PubMed]

38. Huang, L.; Wang, S.A.; DiNardo, C.; Li, S.; Hu, S.; Xu, J.; Zhou, W.; Goswami, M.; Medeiros, L.J.; Tang, G. Tetraploidy/neartetraploidy acute myeloid leukemia. Leuk Res. 2017, 53, 20-27. [CrossRef] [PubMed]

39. Mothersill, C.; Seymour, C.B. Cell-cell contact during gamma irradiation is not required to induce a bystander effect in normal human keratinocytes: Evidence for release during irradiation of a signal controlling survival into the medium. Radiat. Res. 1998, 149, 256-262. [CrossRef]

40. Lepleux, C.; Marie-Brasset, A.; Temelie, M.; Boulanger, M.; Brotin, E.; Goldring, M.B.; Hirtz, C.; Vares, G.; Nakajima, T.; Saintigny, Y.; et al. Bystander effectors of chondrosarcoma cells irradiated at different LET impair proliferation of chondrocytes. J. Cell Commun. Signal 2019, 13, 343-356. [CrossRef]

41. Hu, B.; Wu, L.; Han, W.; Zhang, L.; Chen, S.; Xu, A.; Hei, T.K.; Yu, Z. The time and spatial effects of bystander response in mammalian cells induced by low dose radiation. Carcinogenesis 2006, 27, 245-251. [CrossRef] 